\title{
Las sociedades del ruido
}

\author{
Juliana Pinzón Garrido
}

\section{Resumen}

En el presente escrito se plantea una crítica al excesivo ruido de las sociedades en la era de las tecnologías de la información y la comunicación (TIC). Para ello se propone una ampliación del concepto de ruido que permita incluir el exceso de información propiciado por el alcance omnipotente de las TIC, así como una revalorización del silencio que posibilite configurarlo como condición del pensar libre. Con miras a dichas ampliaciones conceptuales se recurre a José Gimeno y Paul Virilio para delinear los perfiles de la relación entre las TIC y la vida cotidiana, mostrando cómo la creciente dependencia e influencia de la tecnología es una característica cada vez más dominante de la sociedad, que posibilita una comunicación e información excesivas, incesantes, que cada vez se insertan más profundamente en la vida y se niegan a dejarnos solos ni un instante. Posteriormente, para repensar la relación entre ruido y silencio, se acude al músico y filósofo John Cage y a Friedrich Nietzsche. Con su ayuda se establece una relación entre el silencio y el pensamiento. Finalmente, aludiendo al concepto de sociedad de control propuesto por Hardt y Negri en Imperio, se afirma que el ruido que caracteriza a las sociedades contemporáneas puede ser visto como otro modo de control social y político.

Palabras clave: ruido, silencio, reflexión, control, TIC.

\section{NOISE SOCIETIES}

\begin{abstract}
In this paper, a criticism is raised about the excessive noise in societies in the era of information and communication technologies (ICT). In order to do so, an extension of the noise concept is proposed, which allows to include in it the excess of information propitiated by the omnipotent reach of ICT, as well as a revaluation of silence, that allows it to be configured as a condition of free thinking. In views of reaching such conceptual extensions, José Gimeno and Paul Virilio are used to delineate the profiles of the relationship between ICT and everyday life, which shows how the growing dependence and influence of technology is an increasingly dominant feature of society that enables excessive, incessant communication and information, inserted in life and that refuses to leave us alone for a moment. Subsequently, to rethink the relationship between noise and silence, we employ the ideas of musician and philosopher John Cage and Friedrich Nietzsche. With their help, a relationship is established between silence and thought. Finally, referring to the concept of control society by Hardt and Negri in Empire, we
\end{abstract}


propose that the aforementioned noise that characterizes contemporary societies can be seen as another mode of social and political control.

Keywords: noise, silence, reflexion, control, ICT.

\section{Juliana Pinzón Garrido}

Estudiante de octavo semestre de la Licenciatura en Filosofía de la Universidad Pedagógica Nacional de Colombia.

\section{Introducción}

Aún no es del todo clara la distinción entre modernidad y contemporaneidad, pues se debate si la sociedad participa todavía de las dinámicas modernas o si se puede considerar que las problemáticas ya son lo suficientemente particulares para afirmar que se está frente a una época histórica diferente. Es posible, sin embargo, identificar temáticas bastante recientes en la reflexión, como lo son: cambio climático, dependencia de la tecnología, sobreabundancia de información, y control político y de la vida a través de la tecnología (vigilancia). Es precisamente en el marco de una de estas problemáticas que se sitúa el presente escrito, a saber, el contexto de las sociedades determinadas por la tecnología. Se busca plantear una crítica al exceso de ruido que se vive cotidianamente en éstas, proponiendo, por una parte, una relación entre el silencio y la capacidad de pensar libremente y, por otra, entre el ruido y la tecnología, la publicidad y el control político y social. Asimismo, es de interés para el presente trabajo reconsiderar el valor del silencio para la vida en nuestro tiempo.

Para lo anterior se caracterizará, primero, las sociedades contemporáneas como sociedades de la información o determinadas por las tecnologías de la información y la comunicación (TIC). De la mano de José Gimeno y Paul Virilio se profundizará en la influencia de las TIC en ellas. Posteriormente, con la ayuda del músico John Cage y de un fragmento de Así habló Zaratustra de Friedrich Nietzsche, se explorarán los conceptos de ruido y silencio, así como su relación con el pensamiento. Así, se podrá fundamentar, tanto la concepción de las sociedades contemporáneas y sociedades ruidosas, como la necesidad del silencio para el pensamiento. Esas son las premisas fundamentales de este escrito. Finalmente, con todo lo establecido, y haciendo referencia al concepto de sociedad de control propuesto por Hardt y Negri en Imperio, se podrá incluso afirmar que la ruidosa sociedad de la información es una sociedad de control. El texto se divide, entonces, en tres partes: sociedad de la información, sociedad del ruido y, por último, sociedad de control. 


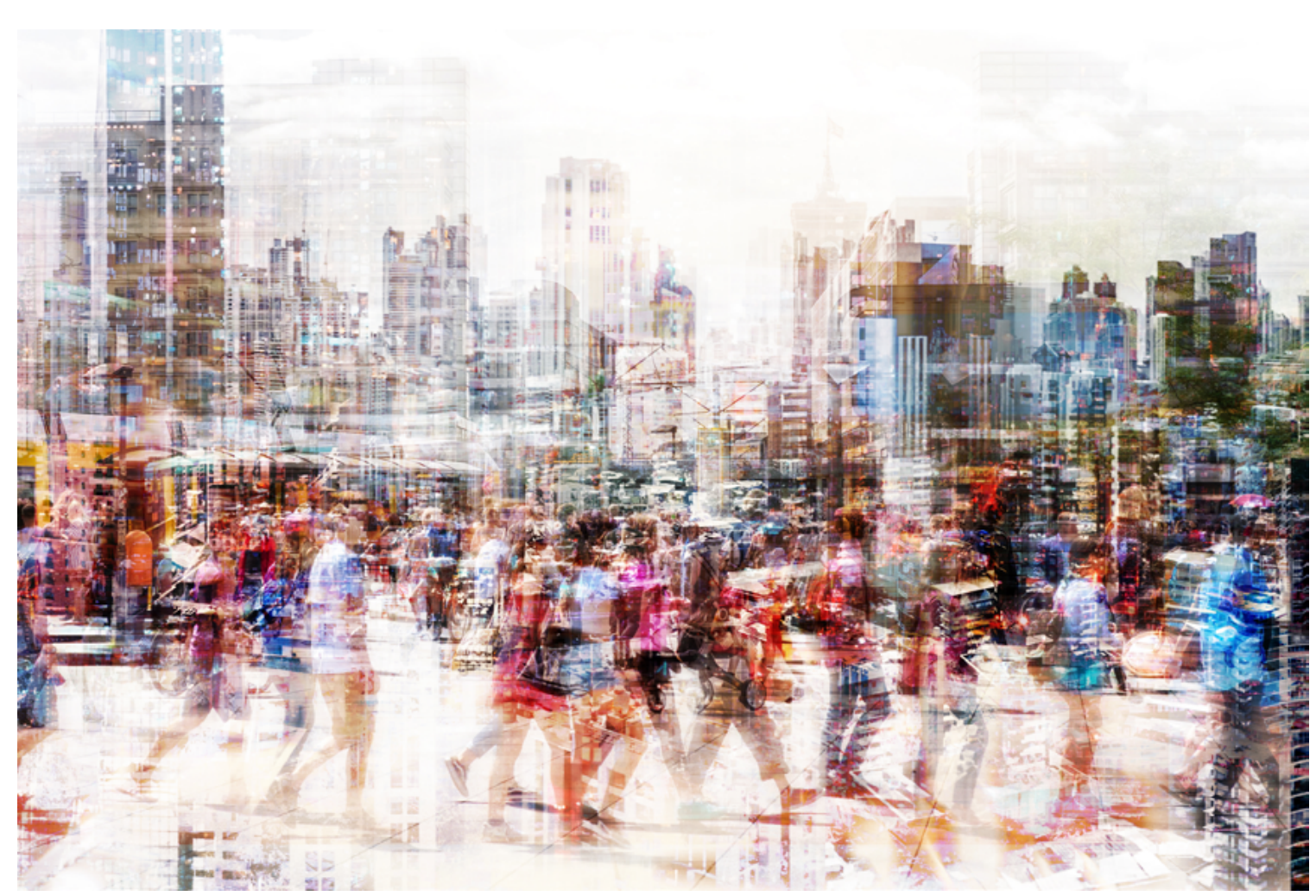

\section{Sociedad de la información}

Las TIc han instaurado, poco a poco, nuevas dinámicas virtuales en el mundo. De esta manera, la información e internet han labrado entre sí una próspera alianza: la información se ha hecho omnipresente e internet es indispensable para acceder a ella. Las tic han conectado al mundo en un entramado virtual donde se hallan dispuestos todos los contenidos posibles. Esta nueva relación entre la información y la tecnología ha creado un espacio en el que el mercado también se ha beneficiado. En efecto, la publicidad, asiento fundamental del consumo, ha encontrado en el mundo virtual un espacio que le permite desarrollarse sin ninguna restricción seria, ya no debe preocuparse de ser ignorada pues, como todo lo virtual, siempre es y siempre está.

Ya diversos autores se han adentrado en el tema, pero en este escrito se acude a José Gimeno y Paul Virilio, principalmente. El primero, en su artículo titulado "Tecnología y educación. ¿Qué hay de nuevo?", presenta a las Tıc como una nueva condición de la cultura que ha extendido su influencia exitosamente a todos los ámbitos de la vida. Afirma que éstas suponen una reconfiguración casi total de los modos de trabajar y relacionarse, que incluso han llegado a poner en debate la necesidad de la escuela y el trabajo como lugares físicos. Las TIC imponen así un orden al que quien no se adecua se vuelve obsoleto. A ellas se atribuye la digitalización de los contenidos, la cual tiene dos caras: por una parte, ha hecho la información más accesible, transferible y fácilmente 
acumulable, pero, por otra, se ha vuelto desordenada y falaz, pues una de las características primordiales del medio virtual es la falta de criterios de organización, clasificación o depuración de objetivos. Por lo tanto, hay más información, pero de menor fiabilidad.

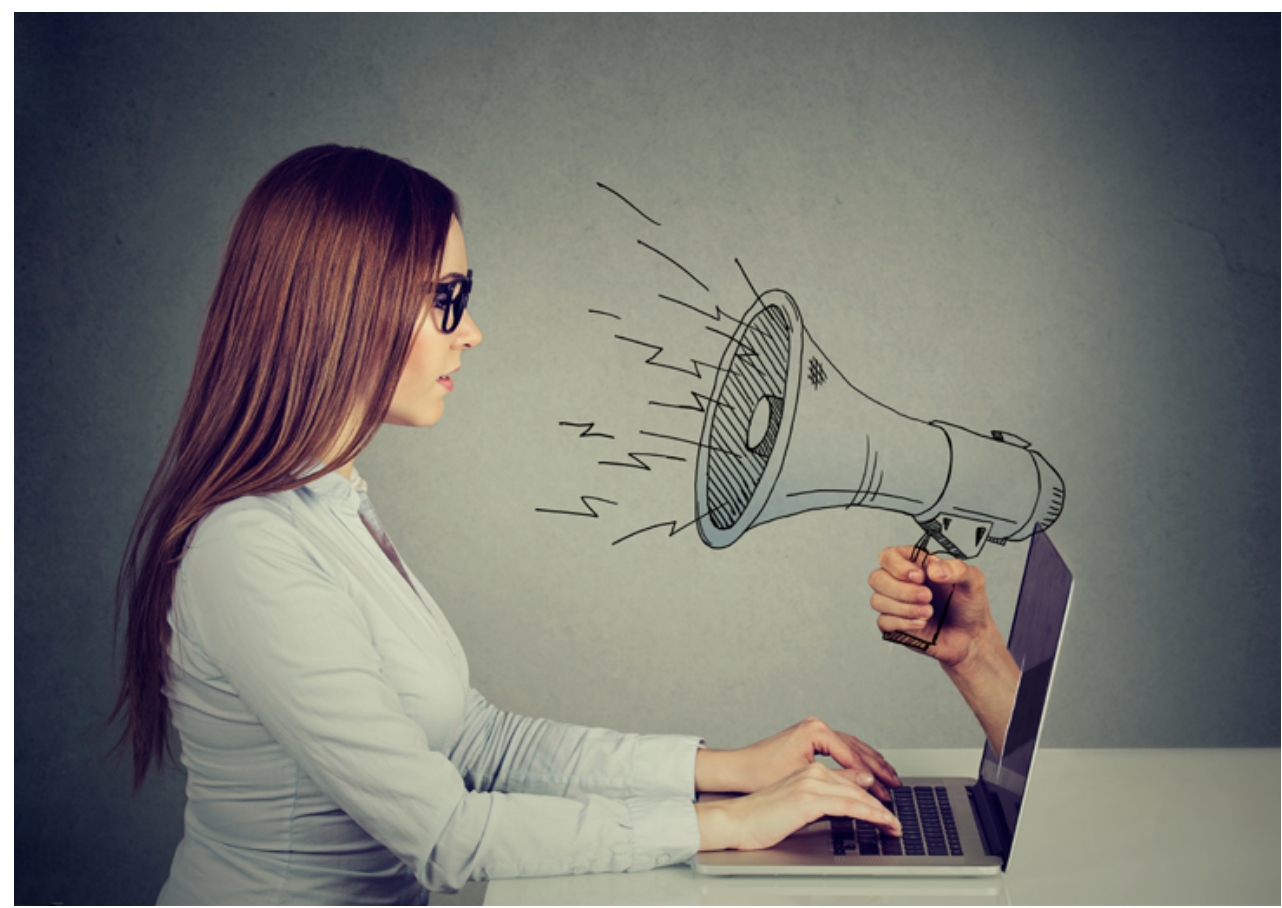

En segundo lugar, se acude a Paul Virilio (2001), quien en su texto El procedimiento silencio muestra, mediante una analogía entre el ruido y el silencio, el cambio que ha sufrido la cultura con las tecnologías de la inmediatez y la virtualidad, que para este autor incluyen la televisión y el cine. Denuncia allí que la tiranía de los medios de comunicación ha desvanecido la cultura de lo oral. La "explosión ensordecedora de lo audiovisual" (Virilio, 2001: 88), pautada en un comienzo por la aparición de tecnologías como el cine y la televisión, significó un silencio paulatino tanto en los espectadores como en las artes plásticas.

Virilio recuerda que el auge de la popularidad de estas tecnologías coincidió con la segunda guerra mundial, con el aburrimiento y desazón de quienes no estaban combatiendo, con la publicidad política fascista de Hitler, con la idealización de los estados y sus héroes patrios, con la desaparición del arte no reproductible. En este hecho histórico puede rastrearse un comienzo del fenómeno de las TIC que, si se lo piensa un poco, son tecnologías eminentemente audiovisuales en la cultura. Las Tic no sólo transforman la forma de trabajar y aprender, como lo muestra Gimeno, sino que también la forma de hacer arte, política y de entretenerse. 


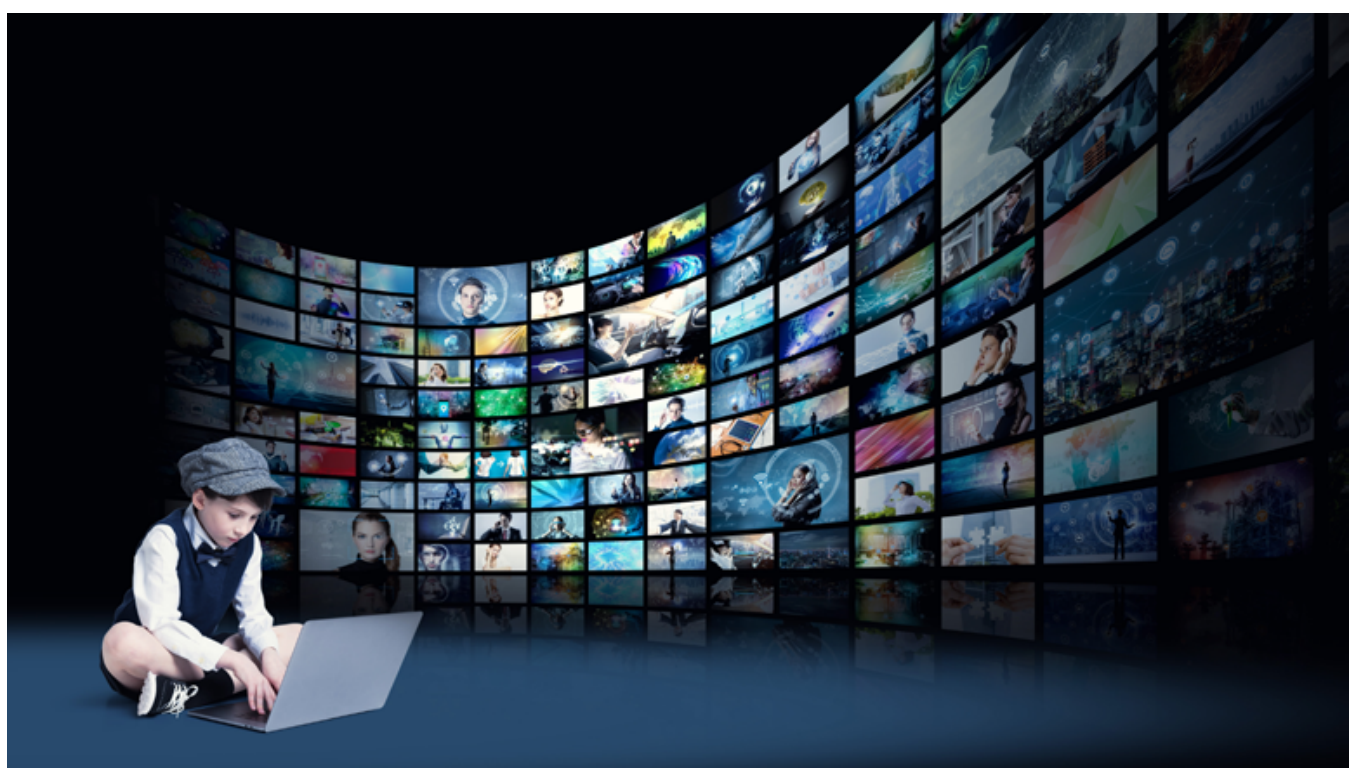

\section{Sociedad del ruido}

Se entiende el ruido como el sonido no armónico, no placentero. Así, es fácil entrever en qué medida las Tıc propician el ruido. En efecto, éstas crean un flujo incesante de información de todo tipo; al igual que cuando hay ruido, no son claros los sonidos, la información en la red no es clara, no es fiable, desarmoniza con su fin informativo. Como se ha visto, las TIC sirvieron como medio de ideologización, fueron mecanismo para imponer el pensamiento nazista y para glorificar a Hitler. Desde esta función política es evidente también que han servido al ruido pues han propiciado el silencio de la oposición política. En este sentido, examinamos a continuación y con más detalle esta semejanza a través de los planteamientos de Virilio y del músico y filósofo John Cage.

Dice Paul Virilio que "desde que aparecen el cine y la televisión [...] el que calla otorga: ningún silencio puede ser reprobador, resistente, sino solamente consentidor" (Virilio, 2001: 91). Esto se explica a través de una concepción del silencio como un derecho a escuchar que, por realizarse como un callar para escuchar, motivó que los medios audiovisuales tomaran la palabra o, mejor dicho, la simularan. Éstos, con sus efectos sonoros, le dieron aires de realidad a la imagen animada, convirtiendo lo audiovisual en una hiperabstracción que, con efectos de realidad, disfrazaron su falta de contenido. Promovieron una velocidad en la forma de presentar y representar que no es natural, y propiciaron un culto a la luz y al sonido que arrebató por completo la voz a los espectadores. 


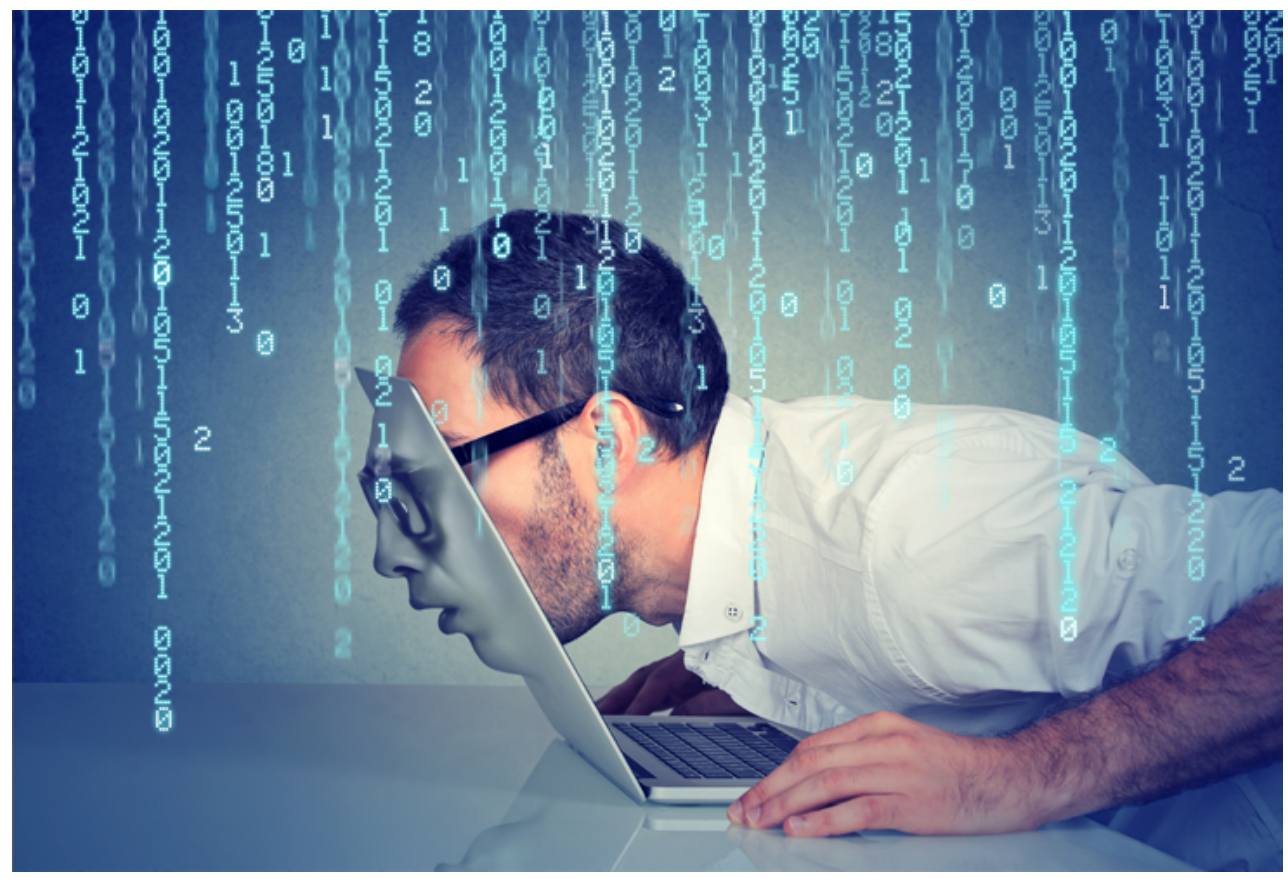

Dice Virilio que hay también una repercusión en el arte de esta influencia mediática. Consiste en la crisis contemporánea del arte que, en su afán por hacerse oír, empezó a gritar haciéndose instantáneo; y, bajo esta nueva forma, ya no requiere mayor atención, ya no dice nada de la subjetividad que la crea. Dice el autor que las Tıc terminarán aboliendo todo diálogo y prohibirán el cuestionamiento. Virilio sitúa con Andy Warhol la denuncia del fin "del hombre del arte: el que habla incluso cuando calla" (2001: 109). Las tic han generado una invalidez imaginaria que redunda en un escepticismo en las facultades creadoras del hombre; la radicalización de ese escepticismo será el resultado del progreso tecnocientífico.

Es necesario distinguir, en Virilio, entre dos connotaciones muy distintas del silencio. El primero le es propio al artista, al que crea, es aquel del que surgen voces, inspiración, y es abismalmente distinto al mutismo, el silencio de los corderos, el que se da frente a cualquier pantalla. A éste último se refiere cuando habla del procedimiento silencio. El mutismo es impuesto por el reinado de lo audiovisual y los medios de comunicación, pues éstos tienden a la saturación de los sentidos y son así un ruido ensordecedor: "el silencio ya no tiene voz, se ha puesto afónico y el mutismo está en su colmo [...] las voces del silencio se han acallado; lo que se ha vuelto actualmente obsceno ya no es tanto la imagen como el sonido o, más bien, la ausencia de sonido" (Virilio, 2001: 89).

Como bien lo dice Virilio el problema radica en la ausencia del silencio, pero no el silencio comprendido del modo usual, como una espera atenta del sonido, sino como un estado con voces propias y diferentes. Ahondemos ahora en el silencio, la cuestión fundamental es saber qué más nos ofrece. De esto depende la gravedad de su ausencia. 


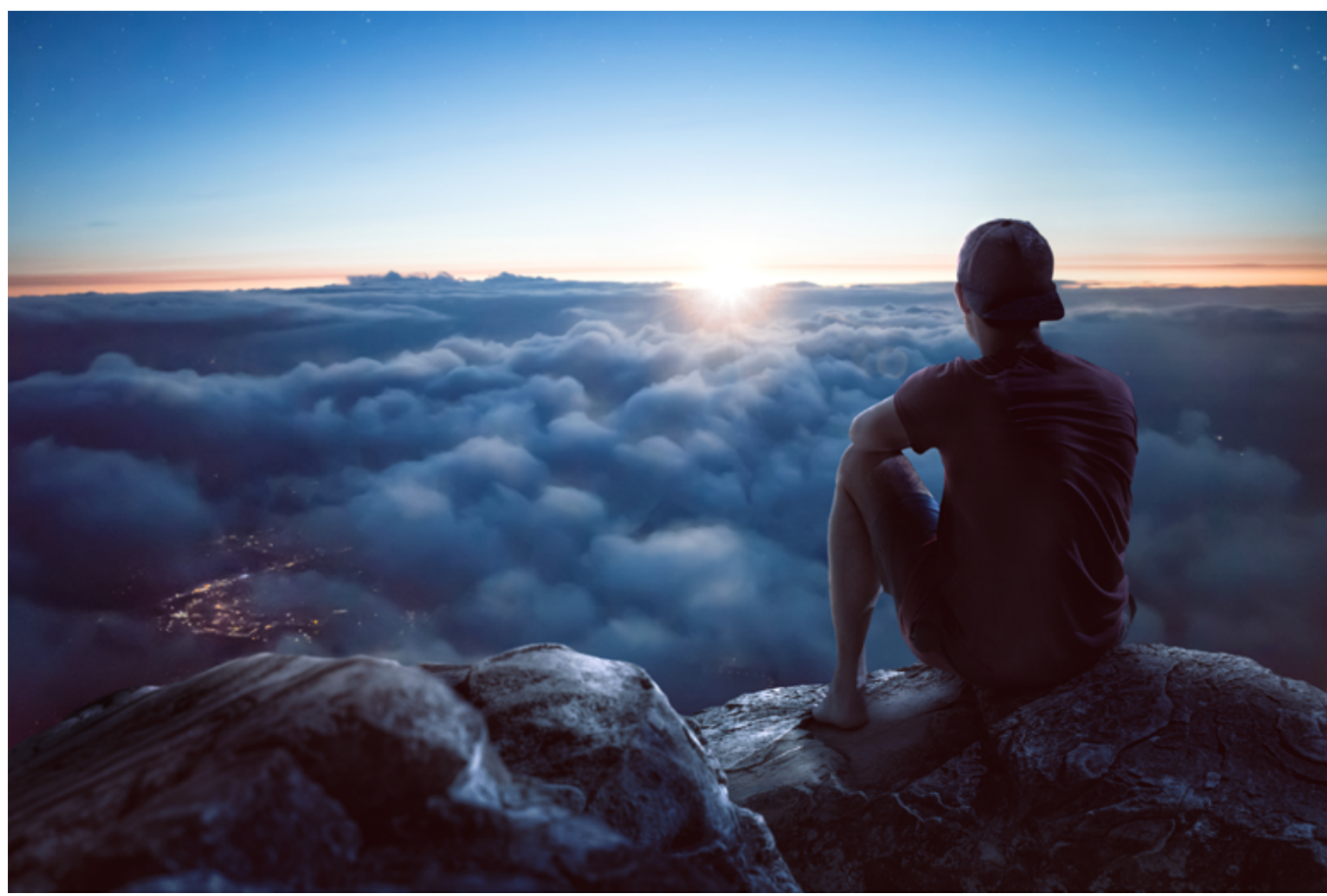

Es en esta instancia donde me valgo de los planteamientos del músico John Cage, de su texto Escritos al oído, en donde afirma que la distinción entre sonido musical, ruido y silencio es intelectual y no sensible. Que, por tanto, hay que ser capaz de apreciar sin jerarquías todos los sonidos, comprendiendo por sonido todo lo que puede ser oído, incluyendo en esta categoría al silencio. Por ello su propuesta presenta al silencio como un estado mental donde no hay intencionalidad, en vez de como un fenómeno acústico.

Con base en sus experiencias en la cámara anecoica de la Universidad de Harvard, Cage descubre que el sonido nunca está ausente, de allí que determina que el silencio es silencio sonoro. La primera consecuencia de esto es que no se debe privilegiar el sonido, sea como habla o pensamiento, por encima del silencio. No se debe comprender el silencio como una pasividad absoluta que no dice nada, sino como otro momento del sonido. De igual manera, la connotación peyorativa de ruido le parece un asunto intelectual, que resulta de la no sujeción de los sonidos a una intencionalidad determinada. Ninguna jerarquía en los sonidos es el principio que permite evaluar el sonido como algo mucho más complejo. Cage aboga por que el sonido puede ser apreciado de manera puramente sensible, sin hacer distinciones, pues sólo aceptando todos los sonidos como iguales es posible entregarse a escuchar. Escuchar es, entonces, una actividad individual que se sitúa en el presente, pues remite a lo que es audible en un momento determinado. Es una manera de estar presente para uno mismo, un estado en donde al no haber intencionalidad se puede estar simplemente deleitado. El silencio es sonoro porque permite escuchar. 
Esta perspectiva del ruido contrasta con la de Virilio, donde es comprendido como un exceso de sonido; sin embargo, me parece posible mezclarlas o matizarlas de modo que puedan converger en una única noción. En efecto, con los planteamientos de Cage se puede evitar caer en una satanización de las TIC, a la cual conduce la equiparación absoluta del ruido con ellas, que establece Virilio. Hay que reconocer que, aunque en su conjunto la información se vuelva ruidosa, considerada individualmente son sólo sonidos a los que escuchar. De modo que el problema no radica sólo en las TIc, sino en esa imposibilidad de oír con claridad, de digerir los contenidos que ellas disponen.

Pero ¿qué es lo que podríamos escuchar en el silencio de las TIC? ¿A qué estaríamos prestando ahora nuestra atención si no es a ellas? Para ir aún más profundo aludo ahora a Nietzsche en Así Hablo Zaratustra. En la conversación de Zaratustra con su hora más silenciosa, ésta lo interpela, lo cuestiona con las preguntas que él no quiere contestar, lo conduce a las respuestas que quiere evadir, lo hace ver lo que caprichosamente niega. Poco a poco lo hace llegar a la conclusión de que no está listo para bajar de la montaña, debe volver a ella para que, en la soledad, el silencio lo pueda seguir instruyendo. El silencio le dice: ";Oh Zaratustra, tus frutos están maduros, pero tú no estás maduro para tus frutos! Por ello tienes que volver a la soledad: pues debes ponerte tierno aún".

Esta reflexión nietzscheana lleva a pensar que con quien habla Zaratustra en su hora más silenciosa es con él mismo, pues ¿quién podría increparlo de manera tan justa como quien lo conoce de siempre, de adentro y de afuera? ¿Quién sino su silencio lo congregará consigo mismo? Lo que encuentra Zaratustra en el silencio es a sí mismo, su propia consciencia que, sin más a qué atender, le revela preguntas y respuestas sobre su vida, le muestra caminos y problemas, lo ayuda a decidir lo que es mejor para sí. Así pues, añadiendo la introspección como cualidad, se puede postular además que el silencio es una condición del pensar. Es éste, entonces, el sentido del silencio sonoro, éstas son las voces del silencio: las propias.

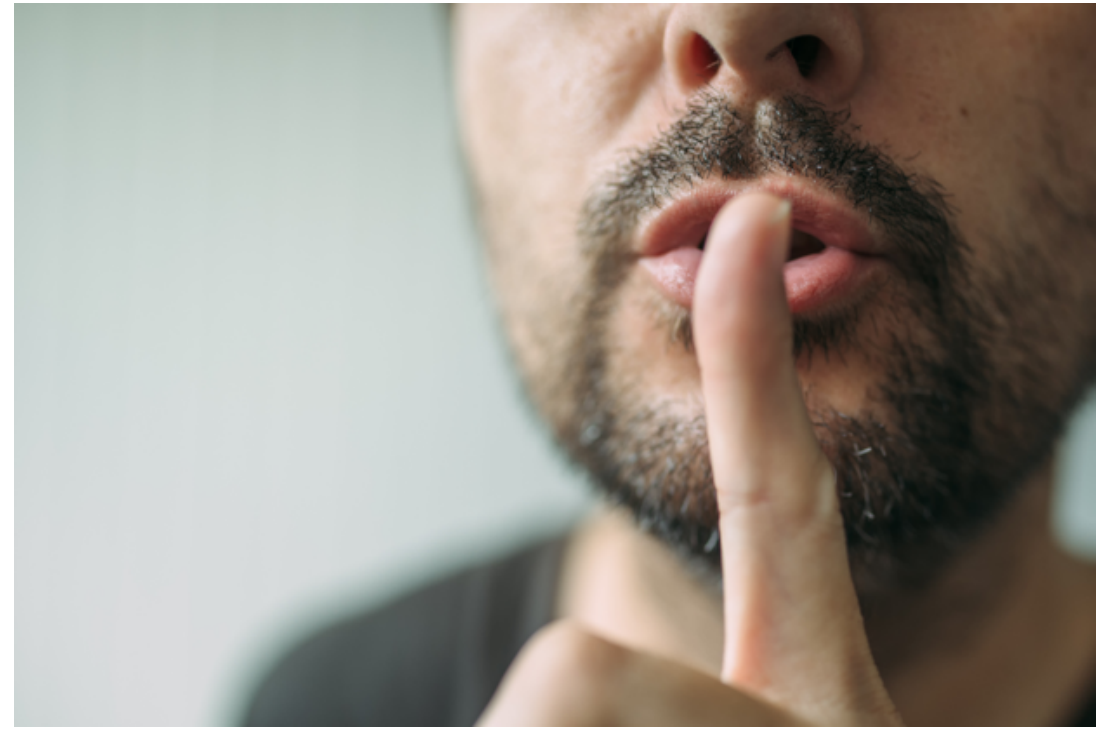




\section{Sociedad de control}

En su texto Imperio, Hardt y Negri plantean que en la posmodernidad ha cambiado el paradigma bajo el cual funciona la sociedad políticamente, pasando de un modo disciplinario, cuyo lugar reside en la modernidad con la aparición de la fábrica, a un modo de control signado por la supremacía de la empresa y sus valores de competitividad. El nuevo imperio es inminente, el control de las personas en la sociedad cambia con la tecnología y con los Estados y los mega-Estados. Poco a poco, el lenguaje de la política y el del mercado se hacen uno. Éste es el panorama que plantean dichos autores, pronostican un imperio analizando el presente político. Se examina ahora el papel que desempeñan las TIC comprendidas como ruido en el ejercicio de control.

En la fábrica se controlaba a las personas en el tiempo y se las ubicaba en el espacio del modo más conveniente para asegurar la productividad, mientras que en la empresa se las controla a través de la numeración y el cifrado. Este cambio supone el afianzamiento del sistema capitalista. Los Estados nación han permitido que el control adquiera tintes de necesidad política, han creado una lógica que naturaliza el control bajo la premisa de la seguridad y la protección. Aparecen sobre el Estado organizaciones que a su vez lo controlan, como la onu, que paulatinamente tiende a volverse un imperio que opera desde valores universales de justicia y cuyo mandato se presenta como eterno y necesario. Su orden es totalizante pues no excluye a ningún individuo, por lo que a su vez requiere un sentido de identidad para con él que asegure una unidad primordial desde la que se legitima el poder. Este nuevo imperio costará la individualidad de las personas pues supone un proceso total de homogeneización.

No es casualidad que estos medios se volvieran el canal de popularidad predilecto de los totalitarismos nacientes, se puede hacer hablar a los medios y es en tal perspectiva que son una estupenda herramienta de control: "la cultura política del siglo xx iba a dedicarse al terreno dudoso del control de las mayorías silenciosas: hacer hablar repentinamente se convertiría en una exigencia mayor con los sondeos de opinión y la medición del rating" (Virilio, 2001: 107).

Si se mira el control político desde el contexto del reinado de las Tic y desde la definición de ruido, se puede decir que supone un orden que hace entrar en detrimento el silencio a través de las TIC, favoreciendo así un ambiente poco reflexivo y poco creativo. El control requiere del mutismo de la gente, busca que se vuelva incapaz de imaginar e incluso incapaz de oír pues, al no haber silencio, se va atrofiando la capacidad de escuchar. Y lo que es peor, la capacidad de escucharse a sí mismo. Tal sería el problema de las tıc en tanto herramienta de control de la vida. 


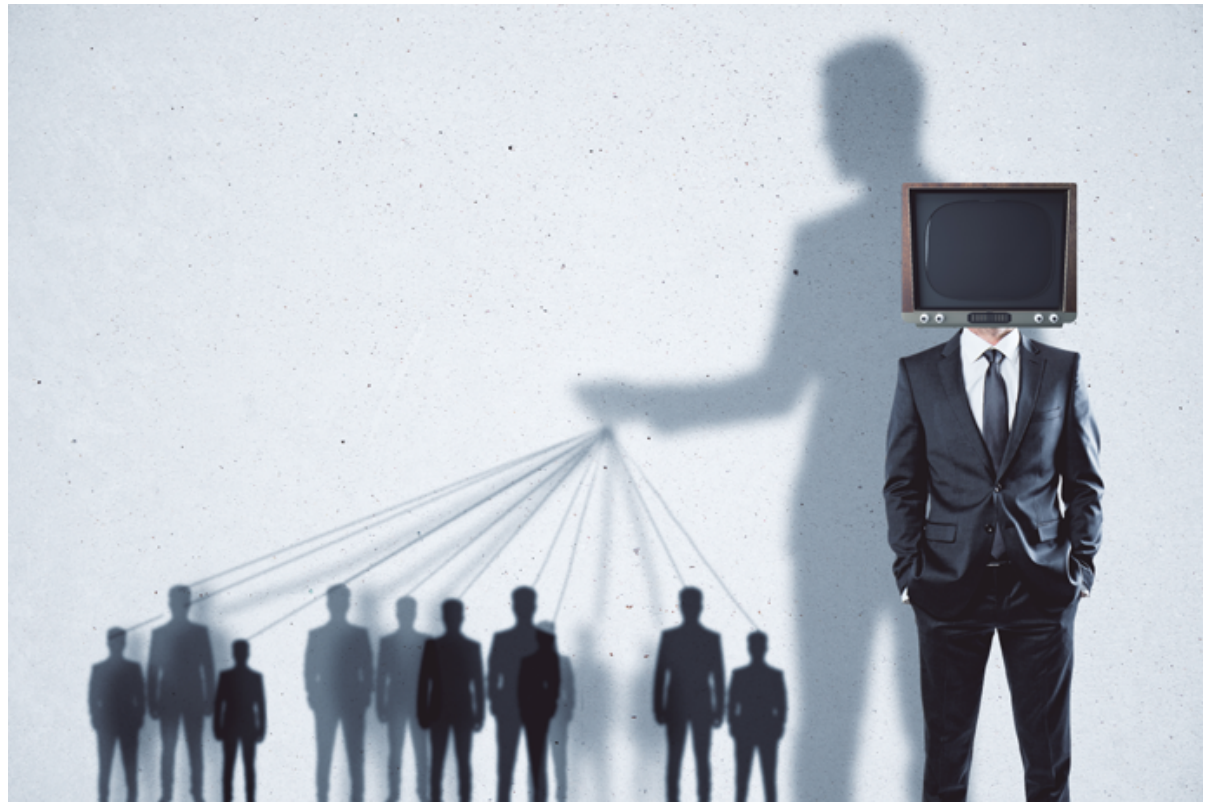

\section{Conclusiones}

¿Cómo, entonces, resistirse a este control? Aquí acudiré finalmente a Deleuze con su interpretación de la filosofía nietzscheana como un problema de fuerzas, donde unas son activas, afirman la vida y la creación, y otras reactivas, pugnan por la conservación y la utilidad. A través de la pregunta trágica se han de valorar las fuerzas que hay en el devenir de los medios audiovisuales y aquel silencio desde el que se concibe toda creación. ¿Quién busca el ruido y lo produce con el exceso de los medios de comunicación? Habrá que decir que se trata de un tipo reactivo, puesto que, como se ha ido mostrando, las tic producen una reacción tal en los espectadores o usuarios, que éstos no pueden atender sino a ellas, viéndose limitados en su capacidad creativa y de escucha, representando así una negación de la vida. Por otro lado, ¿quién habla desde la promoción del silencio? Habrá que decir que, en contraste, se trata de un tipo activo, pues tiende a afirmar la vida a través de la atención a sí mismo en el presente, a escucharse valiéndose del silencio como herramienta fundamental y pugna por la creación.

Deleuze presenta la voluntad de poder como un modo de afirmación de la fuerza activa pues implica un querer que se erige como una potencia de la fuerza, por ello es esencialmente una condición creativa a la vez que crítica. La afirmación de la vida conlleva la creación de nuevos valores y, así, implica una negación de lo ya establecido. Es una transmutación. Desde este concepto también se puede plantear aquella revalorización del silencio, ya que puede ser considerado como una decisión, como una voluntad que revela un nuevo campo de acción para la fuerza. El silencio como una decisión de quien quiere alejarse del ruido de las Tic para sumergirse en sí mismo es una transmutación del valor principal de las sociedades de la información. 
En concordancia con ello se completa la revalorización del silencio que se había planteado como uno de los objetivos de este texto, pues permite precisarlo como un querer. Callar ante una sociedad en la que cada vez es más normal la proliferación irracional de todo no es ya un acto pasivo donde se consiente o se cede la palabra, hacer silencio es ahora tener la voluntad de poner límites a ese estado de cosas, empezando por reducir la influencia que tiene sobre la vida. Es la decisión de depurar los sentidos del exceso de toda aquella información que adviene, para digerirla y quitarle la atención que ha robado a la vida misma. Esta nueva valoración del silencio es, a su vez, una nueva forma de valorar la vida, pues ahora es posible darse cuenta que ha sido descuidada, pues ha perdido nuestra atención. Se ha desatendido la vida en uno de sus rasgos más esenciales: la creación. No sólo la creación de productos artísticos o intelectuales, sino de preguntas y respuestas que incumben sólo a cada uno.

\section{Referencias}

* Cage, John (1999). Escritos al oído. España: Colegio Oficial de Aparejadores y Arquitectos Técnicos de la Región de Murcia.

* Deleuze, Gilles (s.f.). Nietzsche y la Filosofía [versión electrónica]. Recuperado de: $\quad$ http://www.medicinayarte.com/img/biblioteca virtual publica deleuze nietzsche filosofia.pdf.

* Gimeno Sacristán, José (2008). Tecnología y Educación. ¿Qué hay de nuevo? En Guillermo Hoyos Vásquez (Coord.), Filosofía de la educación (pp. 129-156). Madrid: Editorial Trotta.

* Hardt, Michael y Negri, Antonio (2000). Imperio [versión electrónica]. Recuperado de: $\quad$ http://www.infojur.ufsc.br/aires/arquivos/michael\%20hardt\%20-\%20 antonio\%20negri\%20-\%20imperio.pdf.

* Nietzsche, Friedrich (1990). Así hablo Zaratustra. Valencia, España: Editorial Euroliber.

* Virilio, Paul (2001). El procedimiento silencio [J. Fonde, Trad.]. Buenos Aires: Editorial Paidós.

\section{Cómo citar este artículo}

* Pinzón Garrido, Juliana (2019). Las sociedades del ruido. Revista Digital Universitaria (RDU). Vol. 20, núm. 3 mayo-junio. Dol: http://doi.org/10.22201/ codeic.16076079e.2019.v20n3.a6.

Recepción: 01/12/17. Aprobación: 20/03/19. 